\title{
Continuous interscalene brachial plexus blockade provides good analgesia at home after major shoulder surgery-report of four cases
}

\author{
[Le blocage interscalène continu du plexus brachial fournit une bonne analgésie à \\ domicile après une opération majeure à l'épaule - observation de quatre cas]
}

Karen C. Nielsen MD, ${ }^{*}$ Roy A. Greengrass MD FrCP, ${ }^{*}$ Ricardo Pietrobon MD, ${ }^{*}$ Stephen M. Klein MD, ${ }^{*}$ Susan M. Steele MD*

Purpose: Continuous interscalene brachial plexus blockade (CIBPB) in a hospital setting can provide excellent surgical conditions and postoperative analgesia for major shoulder surgery. This is a case report of four patients on the efficacy and advantages of CIBPB for postoperative analgesia at home.

Case reports: Four patients scheduled for rotator cuff repair under CIBPB were discharged home the day of surgery with an interscalene catheter connected to an automated infusion pump administering $0.2 \%$ ropivacaine at $10 \mathrm{~mL} \cdot \mathrm{hr}^{-1}$ for $72 \mathrm{hr}$. Prior to discharge, patients and their attendant were given verbal and written instructions concerning local anesthetic toxicity and explicit contact information for an anesthesiologist or nurse. Outcomes were measured pre- and postoperatively, including verbal analogue pain scores (pain VAS), verbal analogue nausea scores (nausea VAS), side effects, cognitive function (mini-mental state questionnaire), sleep (hours/night), and patient satisfaction (Likert scale). Postoperative VAS scores over three days were very low. Two patients reported only one episode of nausea. There were no complications associated with local anesthetic toxicity or catheter use. Cognitive function improved over three days. Sleep increased from a mean of five hours before surgery to seven hours over the next three nights. Patient satisfaction with care was high. Significant cost savings were documented.

Conclusion: The use of CIBPB for $72 \mathrm{hr}$ in patients undergoing major ambulatory shoulder surgery can result in good analgesia with minimal opioid requirement, cost savings and possibly improvement in outcome measures.
Objectif: Le blocage interscalène continu du plexus brachial (BICPB) réalisé en milieu hospitalier peut créer des conditions chirurgicales et une analgésie postopératoire excellentes en cas d'intervention majeure à l'épaule. Nous présentons l'étude de l'efficacité et des avantages du BICPB réalisé pour l'analgésie à domicile chez quatre patients.

Éléments cliniques : Quatre patients opérés pour la réparation de la coiffe des rotateurs sous BICPB ont quitté l'hôpital le jour de l'intervention avec un cathéter interscalène branché à une pompe à perfusion automatisée qui administrait de la ropivacaïne à $0,2 \%$ à raison de $10 \mathrm{~mL} \cdot \mathrm{h}^{-1}$ pendant $72 \mathrm{~h}$. Avant le départ, les patients et leur accompagnateur ont reçu des consignes verbales et écrites sur la toxicité de l'anesthésique local et des informations claires permettant de communiquer avec un anesthésiologiste ou une infirmière. Les résultats, mesurés avant et après l'opération, comprenaient les scores de douleur selon l'échelle visuelle analogique (EVA douleurs), les scores verbaux analogues de nausées/vomissements (EVA nausées), les effets secondaires, la fonction cognitive (mini-questionnaire de l'état mental), le sommeil (heures/nuit) et la satisfaction du patient (échelle de Likert). Les scores postopératoires de l'EVA ont été très bas pendant les trois jours. Deux patients ont connu un épisode de nausées. Aucune complication reliée à la toxicité de l'anesthésique local ou à l'usage du cathéter n'a été mentionnée. La fonction cognitive s'est améliorée au cours des trois jours. Le temps de sommeil s'est accru d'une moyenne de cinq heures avant l'opération à sept heures pour les trois nuits suivantes. Les patients ont été très satisfaits des soins et une réduction des coûts significative a été enregistrée.

Conclusion : L'usage de BICPB pendant $72 \mathrm{~h}$ chez des patients qui subissent une opération ambulatoire majeure à l'épaule peut produire une analgésie adéquate avec des besoins minimaux d'opioïdes, une réduction des coûts et une amélioration possible des mesures des résultats.

From the Departments of Anesthesiology, ${ }^{*}$ and Surgery, $\dagger$ Duke University Medical Center, Durham, North Carolina, USA.

Address correspondence to: Dr. Karen C. Nielsen, Department of Anesthesiology, Box 3094, Duke University Medical Center, Durham, NC 27710, USA. Phone: 919-668-2051; Fax: 919-668-2081; E-mail: niels006@mc.duke.edu

Presented in part (poster presentation) at the $5^{\text {th }}$ Annual Meeting of the Latin American Society of Regional Anesthesia (LASRA), August 2000, São Paulo, Brazil, and at the $51^{\text {st }}$ Annual Meeting of the American Society of Anesthesiologists, San Francisco, CA October, 2000. The $2^{\text {nd }}$ prize in the best poster competition was awarded to this presentation by the Latin American Society of Regional Anesthesia.

Accepted for publication May 27, 2002.

Revision accepted September 9, 2002. 
$M$

AJOR surgical procedures involving the shoulder such as rotator cuff repair are often associated with severe postoperative pain. Analgesic treatment frequently requires large doses of iv opioids and inpatient admission. ${ }^{1}$ Severe pain may also compromise the postoperative rehabilitation that is necessary for a good functional outcome. Continuous interscalene brachial plexus blockade (CIBPB) is an alternative treatment that can provide better postoperative analgesia compared to single injection nerve block or iv opioid. ${ }^{2}$

Recently, several groups have published data on the efficacy of continuous ambulatory infusion of local anesthetics at home. ${ }^{3-5}$ In these reports, profound analgesia was obtained resulting in an opioid sparing effect for upper and lower extremity surgery. Despite these encouraging results little information regarding outcome was provided to support using these novel interventions in an ambulatory setting. To justify this type of regional technique in ambulatory patients, it is necessary to demonstrate improvement in outcome as well as safety when compared with conventional general anesthetic and oral analgesic regimens. Given the currently accepted treatments, Todd and Brown in their recent editorial emphasized the need for outcome data and stated "more work is needed to prove that such (regional) techniques really offer measurable advantages over other methods..." ${ }^{6}$ In addition, due to the constant pressures from the healthcare system for cost containment, it is also necessary to show the potential cost benefits associated with ambulatory techniques leading to early hospital discharge. This report describes four patients undergoing major shoulder surgery in an ambulatory setting who were discharged home with a continuous interscalene catheter for $72 \mathrm{hr}$ after surgery.

\section{Case reports}

Four patients classified as American Society of Anesthesiologists (ASA) physical status II $(n=3)$ and III $(n=1)$ and with a mean age of $45 \mathrm{yr}$ of age (ranging from 47-68), were scheduled for unilateral open rotator cuff repair under CIBPB with iv sedation. Three patients lived within 30 miles from our institution and one patient stayed in a hotel close to the hospital during the first four postoperative days.

On the day prior to surgery, all patients received a visit from a home infusion services nurse. Nurses evaluated the home environment and its adequacy, provided patient education about the infusion pump, and provided information about the routine postoperative care. Each patient was called by an anesthesiologist who offered additional information about the anes- thetic technique and the potential risks of a local anesthetic infusion via an indwelling catheter. Pre-existing pain was measured using a verbal analogue pain scale (VAS) at rest $(0=$ no pain; $10=$ worst pain imaginable. $)^{7}$ All medications used for pain control were recorded. Cognitive function was tested using the modified mini-mental state, which includes basic orientation, language, short-term memory, and ability to calculate. ${ }^{8}$ Anxiety was evaluated using the modified hospital anxiety and depression scale. ${ }^{9}$ Number of hours of sleep per night was also assessed.

On the day of surgery, patients were brought to the preoperative holding area where the anesthetic plan was discussed. After application of standard ASA monitors and administration of supplemental oxygen by facemask, patients were sedated with iv midazolam ( $1-5 \mathrm{mg}$ ) and fentanyl $(50-250 \mu \mathrm{g})$, titrated to moderate sedation (arousable on command). All interscalene blocks were performed using the approach previously described by Winnie ${ }^{10}$ using the Braun Contiplex® (B. Braun Medical, Bethlehem, PA, USA) insulated Tuohy system (Figure).

Using this needle and a nerve stimulator, a motor response was sought distal to the shoulder. After an appropriate motor response in the deltoid or biceps muscle was localized with the lowest achievable current (goal less than $0.5 \mathrm{~mA}$ ), a $30-40 \mathrm{~mL}$ solution of $0.5 \%$ ropivacaine with epinephrine 1:400 000 was incrementally injected. Maintaining the needle in the same position, a 20 -gauge standard end-hole epidural catheter was threaded $5 \mathrm{~cm}$ past the tip of the needle. The catheter was secured with medical adhesive, cutaneous adhesive sutures (Ethicon, Somerville, NJ, USA), and an occlusive dressing. The catheter was then aspirated for blood and a $3-\mathrm{mL}$ test dose using the same local anesthetic was given. An intercostobrachial nerve block was then performed separately using $10 \mathrm{~mL}$ ropivacaine, $0.5 \%$, with epinephrine 1:400 000. Successful neural blockade was documented approximately ten minutes after block placement by loss of shoulder abduction. The neural blockade provided a complete motor, sensory, and sympathetic block of shoulder and arm in all patients. Patients were taken to the operating room for surgery. Intraoperative sedation was provided with iv propofol $\left(20-40 \mu \mathrm{g} \cdot \mathrm{kg}^{-1} \cdot \mathrm{min}^{-1}\right)$, titrated to moderate sedation (arousable to commands).

At the conclusion of surgery, all patients were transferred to the postanesthesia care unit (PACU). On arrival, the catheter was aspirated and an initial bolus of $0.2 \%$ ropivacaine with $1: 400000$ epinephrine $10 \mathrm{~mL}$ was given to check for accidental $i v$ placement. In addition, an automated infusion pump (Abbott Aim ${ }^{\circledR}$ Plus-Ambulatory Infusion Manager, Abbott 


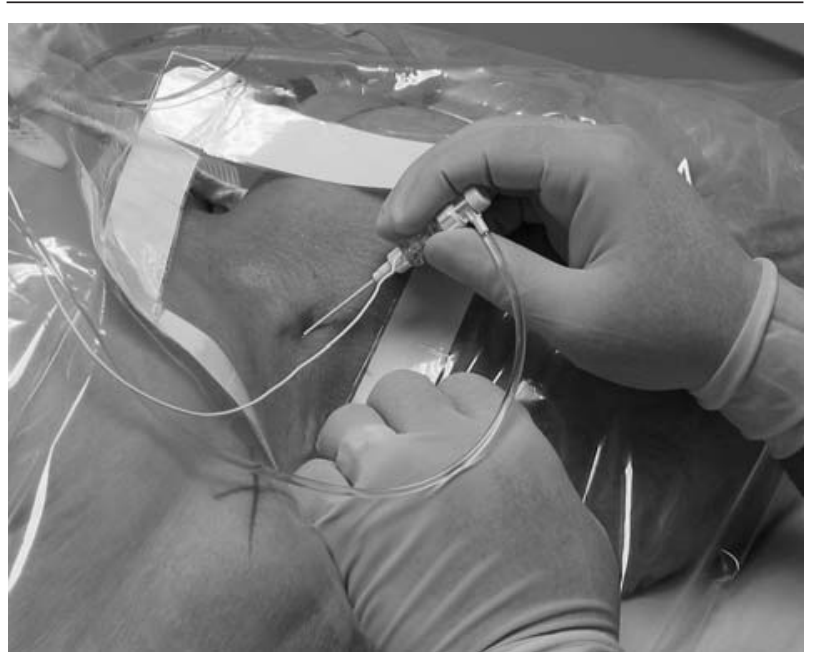

FIGURE Needle positioning and antero-lateral orientation of the bevel during continuous interscalene brachial plexus blockade placement for surgery on the left shoulder.

Laboratories Inc, San Diego, CA, USA) with an infusion bag containing $800 \mathrm{~mL}$ of $0.2 \%$ ropivacaine was connected to the interscalene catheter. The infusion bag was large enough to keep the system closed during the 72-hr infusion, avoiding system opening and bag switch, thus facilitating its management at home. The pump continuously infused $0.2 \%$ ropivacaine at $10 \mathrm{~mL} \cdot \mathrm{hr}^{-1}$. Although the combination of a basal continuous infusion with patient controlled analgesia (PCA) feature has been reported as the recommended type of infusion regimen, ${ }^{11}$ the logistics of our practice at the time of this pilot trial did not allow patients to have PCA available at home. Patients were given written and verbal instructions about signs and symptoms of local anesthetic toxicity, clamping of the pump tubing in such case, possible problems with the infusion pump, and the name of a person to contact for any questions or problems (home infusion services nurse and a staff anesthesiologist). All patients were directed to take oral celecoxib $200 \mathrm{mg}$ once a day for one week. Patients were also given a prescription for oral oxycodone $5 \mathrm{mg}$ to take if necessary. When patients met standard PACU discharge criteria they were discharged home.

A registered nurse and an anesthesiologist made one daily home visit during the first three postoperative days to evaluate the effectiveness in controlling postoperative pain and the adequacy/safety of the home environment. Follow-up information was obtained by an anesthesiologist via telephone calls at
$24 \mathrm{hr}, 48 \mathrm{hr}, 72 \mathrm{hr}$ and seven days after surgery. Data points include: pain VAS, supplemental opioid consumption, and side effects. Nausea was measured by a verbal rating scale ${ }^{12,13}$ modified to a $0-10$ scoring system $(0=$ no nausea; $10=$ worst nausea imaginable $)$. Pain, nausea and side effect data were recorded in one daily punctual measurement. Cognitive function, sleep and anxiety were re-measured, as well as patient satisfaction regarding anesthesia, postoperative pain control, and early home discharge $(0=$ extremely dissatisfied; $10=$ extremely satisfied).${ }^{14}$

Two patients reported pain VAS scores of zero at each measurement and used no oxycodone. The other two patients reported only one episode of breakthrough pain, which was controlled by an increase in the infusion rate to $12 \mathrm{~mL} \cdot \mathrm{hr}^{-1}$ and the use of oral oxycodone as prescribed (5-10 mg every four hours if necessary). There were no complications due to local anesthetic toxicity or catheter use such as dislodgment, migration or infection. Two patients reported no nausea at any time in the study period. Of the other two, one became nauseated in PACU, requiring treatment with $i v$ ondansetron $4 \mathrm{mg}$ whereas the other had a previous history of motion sickness and became nauseated during the car ride home.

Cognitive function scores improved in all patients from an initial preoperative mean of 18.8 points to 21.6 points at postoperative day three (higher scores indicate better cognitive function). All patients reported sleep impairment because of nocturnal pain in the preoperative period. Number of hours of sleep per night increased in all patients from a mean of five hours before surgery to seven hours over the first three postoperative days. Anxiety levels decreased from a preoperative mean score of 1.7 to 0.1 at postoperative day three. Patient satisfaction with care was high. Each nursing home visit costs approximately US $\$ 80$.

\section{Discussion}

The results of this initial experience using CIBPB for shoulder surgery in the home setting suggest that this technique can be effective in the postoperative pain control of major ambulatory surgeries. Pain VAS scores and opioid consumption over $72 \mathrm{hr}$ were low.

In our institution, more than 800 CIPBP were performed in the last three years. In this large series, the failure rate related to this technique was low $(4.8 \%$; unpublished data). Compared to the single injection technique, the needle positioning is slightly more caudal and the bevel of the needle is oriented antero-laterally (Figure). This technical variation facilitates an adequate catheter insertion into the brachial plexus sheath of approximately $5 \mathrm{~cm}$. Also, we believe the 
technique described in our report to secure the catheters is responsible for the low rates of catheter dislodgment and absence of catheter migration.

Although several previous experiences with ambulatory continuous peripheral nerve blockade have been reported, ${ }^{3-5}$ their impact on sleep and cognitive function remains unclear. Our results in four patients regarding improvement in sleep and cognitive function are still preliminary and preclude a definitive conclusion. Of notice, all four patients reported decreased sleep due to nocturnal pain in the preoperative period. These patients demonstrated an improvement in sleep and cognitive function during the postoperative period. Sleep and cognitive function can be impacted by numerous perioperative factors, including general anesthesia, pain, analgesic (opioid) treatment and the environment. ${ }^{15,16}$ Patients in our study maintained an enhanced cognitive function while increasing the number of hours of sleep. This finding suggests that CIPBP can be one of the factors associated with the avoidance of these common postoperative events. Recovery in a home setting can also potentially avoid preventable causes of postoperative sleep disturbances such as hospital noise from staff conversations, machines/equipment, nocturnal observation, and frequent therapeutic procedures performed by nurses. ${ }^{17}$ The improved cognitive function scores are most likely associated with the home convalescence, adequate analgesia with minimal opioid use, and improved sleep profile. ${ }^{17}$ Given the enhancement in sleep and cognitive function, a comparison between CIPBP and other more conventional anesthetic techniques and analgesic regimens in a larger randomized trial would be essential to determine the magnitude of this association.

Supporting the improved convalescence obtained with this treatment algorithm is the decreased postoperative anxiety in the postoperative period compared to preoperative levels. While a successful completion of the surgical procedure is an important factor decreasing anxiety, pain would arguably increase anxiety levels.

Extensive resources such as home care nursing and physician visits were used to assess the feasibility of the home catheter program. This structure enabled the detailed evaluation of safety, logistics and outcome. Despite the available assets, little intervention was necessary to maintain the analgesia at home, which suggests that extending the technique to a larger population is possible. Our costs associated with nursing home visits were lower than those associated with one or two-day hospital stay, which is the standard care after this type of surgical procedure. In our institution, the cost of four home visits performed for each patient was $12.8 \%$ of the total cost associated with a one- day hospital stay. The cost of physician home visits was not measured in our study since they were performed as an additional safety measure that will no longer be required in the continuation of this program.

In conclusion, adequate postoperative analgesia was achieved with CIBPB for $72 \mathrm{hr}$ after major ambulatory shoulder surgery, with a low incidence of side effects, minimal maintenance and important cost savings. The improvement in outcome measures should be evaluated in larger randomized studies to evaluate the effectiveness of CIBPB in controlling pain and decreasing adverse effects compared with conventional techniques.

\section{References}

1 Chung F, Mezei G. Adverse outcomes in ambulatory anesthesia. Can J Anesth 1999; 46: R18-26.

2 Tuominen M, Haasio J, Hekali R, Rosenberg PH. Continuous interscalene brachial plexus block: clinical efficacy, technical problems and bupivacaine plasma concentrations. Acta Anaesthesiol Scand 1989; 33: 84-8.

3 Rawal N, Axelsson K, Hylander J, et al. Postoperative patient-controlled local anesthetic administration at home. Anesth Analg 1998; 86: 86-9.

4 Klein SM, Greengrass RA, Gleason DH, Nunley JA, Steele SM. Major ambulatory surgery with continuous regional anesthesia and a disposable infusion pump. Anesthesiology 1999; 91: 563-5.

5 Ganapathy S, Amendola A, Lichfield R, Fowler PJ, Ling $E$. Elastomeric pumps for ambulatory patient controlled regional analgesia. Can J Anesth 2000; 47: 897-902.

6 Todd MM, Brown DL. Regional anesthesia and postoperative pain management: long-term benefits from a short-term intervention (Editorial review). Anesthesiology 1999; 91: 1-2.

7 Breivik EK, Björnsson GA, Skovlund E. A comparison of pain rating scales by sampling from clinical trial data. Clin J Pain 2000; 16: 22-8

8 Folstein MF, Folstein S, McHugh PR. Mini-mental state. A practical method for grading the cognitive state of patients for the clinician. J Psychiatr Res 1975; 12: $189-98$.

9 Zigmond AS, Snaith RP. The hospital anxiety and depression scale. Acta Psychiatr Scand 1983; 67: 361-70.

10 Winnie AP. Interscalene brachial plexus block. Anesth Analg 1970; 49: 455-66.

11 Singelyn FJ, Seguy S, Gouverneur JM. Interscalene brachial plexus analgesia after open shoulder surgery: continuous versus patient-controlled infusion. Anesth Analg 1999; 89: 1216-20. 
12 Melzack R, Rosberger Z, Hollingsworth ML, Thirlwell M. New approaches to measuring nausea. CMAJ 1985; 133: 755-8, 761 .

13 Boogaerts JG, Vanacker E, Seidel L, Albert A, Bardiau $F M$. Assessment of postoperative nausea using a visual analogue scale. Acta Anaesthesiol Scand 2000; 44: 470-4.

14 Di Palo MT. Rating satisfaction research: is it poor, fair, good, very good, or excellent? Arthritis Care Res 1997; 10: 422-30.

15 Rosenberg-Adamsen S, Keblet H, Dodds C, Rosenberg J. Postoperative sleep disturbances: mechanisms and clinical implications. Br J Anaesth 1996; 76: 552-9.

16 Closs SJ. Patients' night-time pain, analgesic provision and sleep after surgery. Int J Nurs Stud 1992; 29: 381-92.

17 Canadian Medical Association. US hospital seeks ways to let patients have undisturbed sleep. CMAJ 1994; 150: 1286.

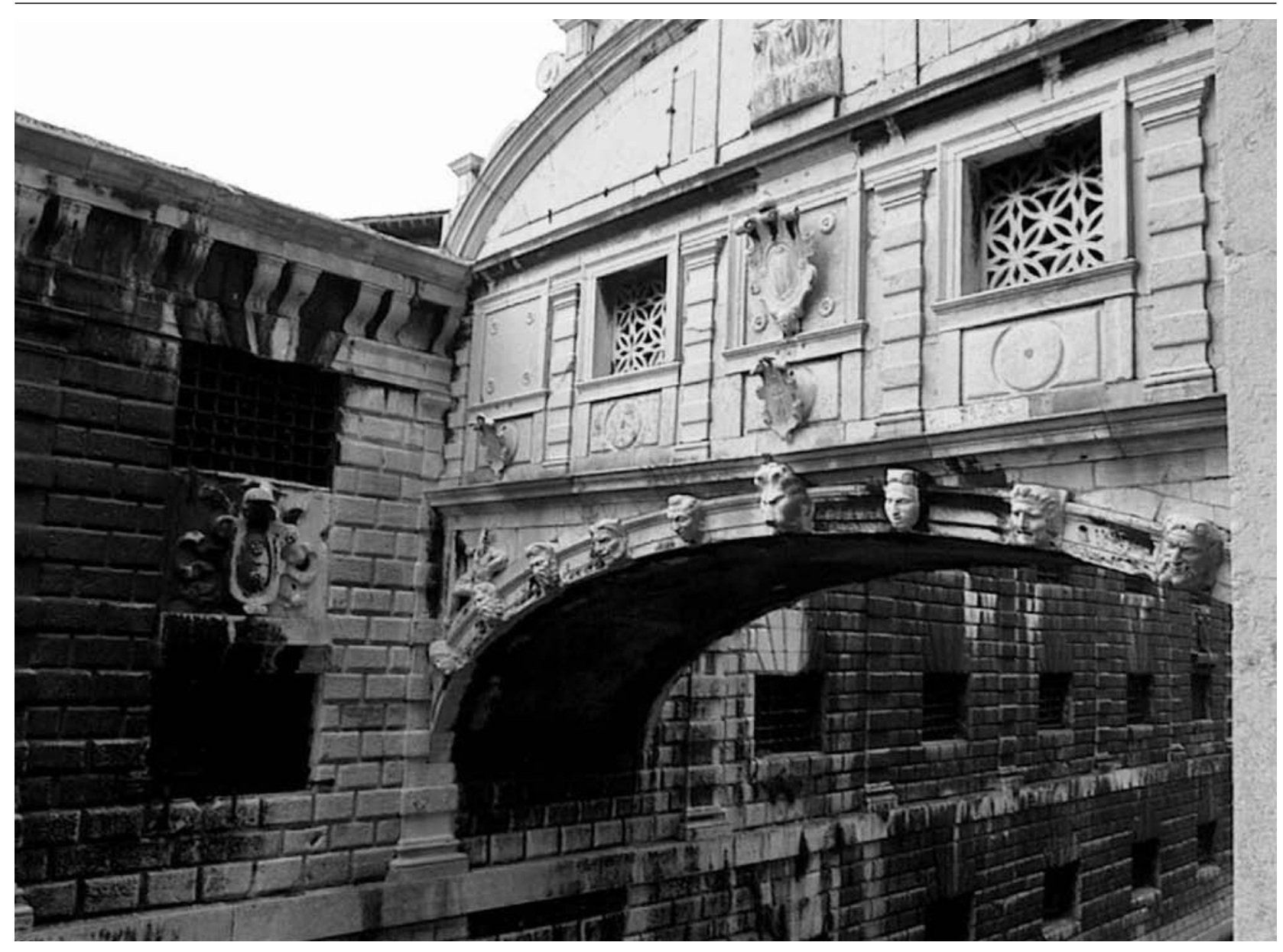

Le Pont des Soupirs - Venise, Italie 